\title{
Transitional cell carcinoma of the nasolacrimal sac
}

\author{
This article was published in the following Dove Press journal: \\ Clinical Ophthalmology \\ 19 October 2009 \\ Number of times this article has been viewed
}

\section{Rushmia Karim \\ Raf Ghabrial \\ Betty Lin}

University of Sydney, Concord Repatriation General Hospital, Sydney, New South Wales,

Australia
Correspondence: R Karim

Concord Repatriation General Hospital, Hospital Rd, Concord West NSW

2138, Australia

Email rushmiak@gmail.com
Abstract: Tumors in the lacrimal sac are rare yet important due to their malignant and potentially lethal outcomes if there is a misdiagnosis or delay in treatment. Epithelial tumors predominate with squamous cell carcinoma. We report a transitional cell carcinoma of the lacrimal sac and management course for the patient.

Keywords: transitional cell carcinoma, nasolacrimal sac, nasolacrimal duct

\section{Case report}

A 58-year-old female presented with a six-month history of left-sided epiphora to the ophthalmologist. There were no associated symptoms of sinus disease including frontal headaches, rhinorrhea, postnasal drip, or nasal congestion. The patient's vision had not changed during this period of time with visual acuity recorded as $6 / 6$ in both eyes. There was no purulent or hemorrhagic discharge from the left tear duct. The patient had a history of hypertension, hyperlipidemia, and gastroesophageal reflux disease controlled by pharmacotherapy.

Examination revealed a painless swelling of the left lacrimal sac compared to the right. This had not been noticed by the patient previously. Probing and syringing of the left lacrimal system revealed obstruction. Oral antibiotics and lubricant eye drops were prescribed. With a preliminary diagnosis of dacryocystitis and nasolacrimal duct obstruction, a nasoendoscopic dacryocystorhinostomy was performed in January 2007.

During surgical exploration the lacrimal sac was documented to be swollen at $20 \mathrm{~mm}$ in length. A mass lesion was suspected due to the increased size and change in consistency of the lacrimal sac. A mucosal biopsy was completed and a nasolacrimal tumor was suspected from the pathology. Surgical biopsies of the nasolacrimal sac are not routinely performed in dacryocystorhinostomy unless malignancy is suspected pre- or perioperatively. This mass was confirmed on the computed tomography scan postprimary dacryocystorhinostomy (Figure 1).

Planned revision surgery in March 2007 confirmed an infiltrative mass in the enlarged lacrimal sac. The lacrimal sac did not significantly increase in size during the two-month interval between primary dacryocystorhinostomy and revision surgery. Removal of the left lacrimal sac, nasolacrimal duct, and canaliculi were performed using both nasoendoscopic and external approaches (Figure 2). The entire lacrimal apparatus including the two upper and lower lid canaliculi, lacrimal sac and duct was resected intact and the gross specimen sent for histopathology (Figure 3). 


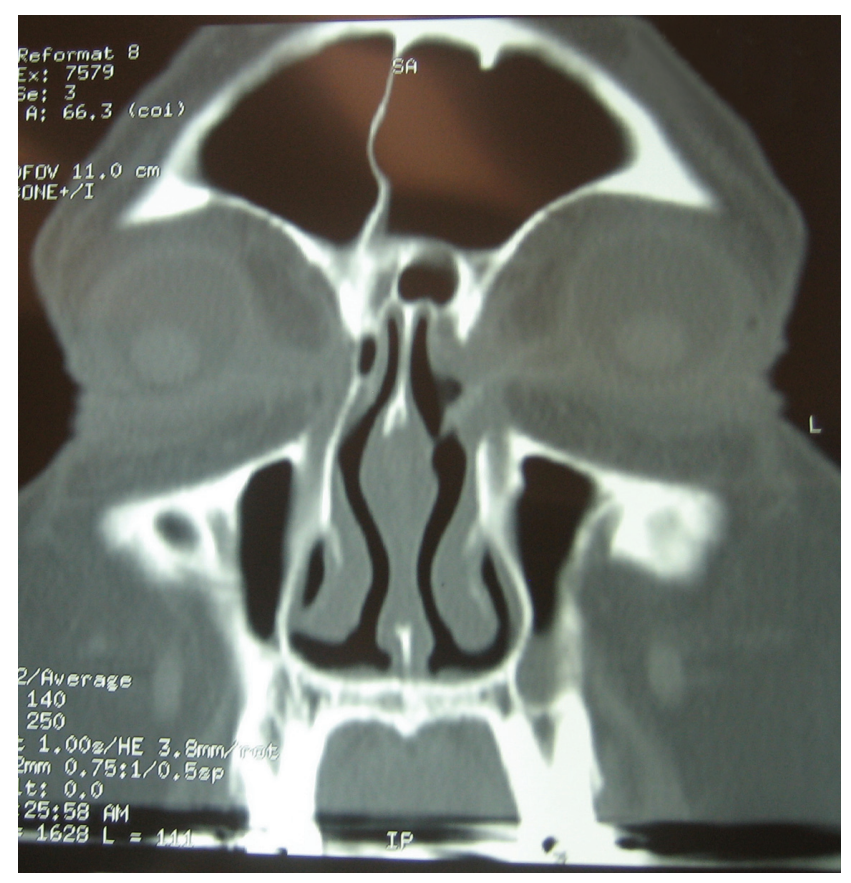

Figure I Computed tomography of the coronal view demonstrating the blockage of the ostiomeatal complex. A medial mass lesion at the lacrimal sac is noted. A bony osteium in the lacrimal bone is apparent from the first initial external dacryocystorhinostomy providing patency into the nasolacrimal duct.

A reconstruction with island and rotational flap was performed to achieve full closure and the desired cosmetic effect. Associated functional endoscopic sinus surgery (FESS), septoplasty, and medial maxillectomy was performed by the otolaryngologist.

\section{Histopathology}

The nasolacrimal sac was lined by a malignant papillary epithelial tumor with distinct features of transitional

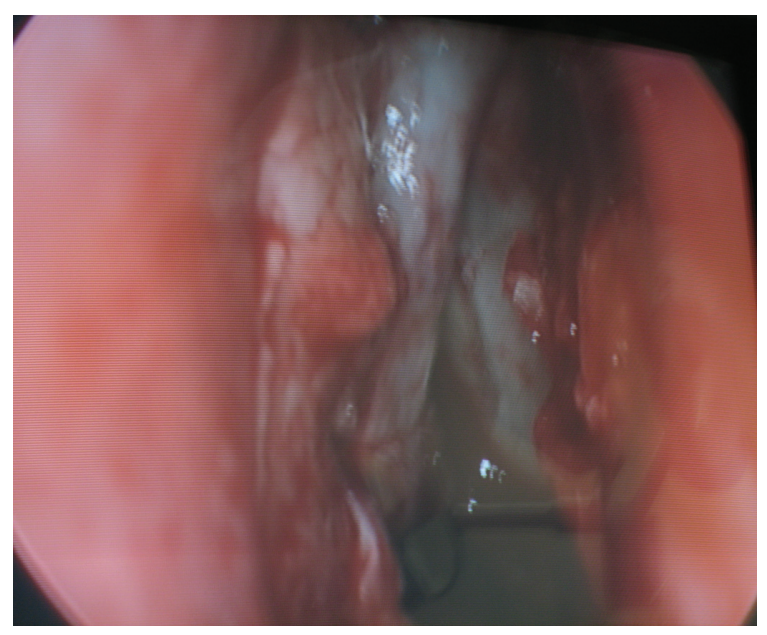

Figure 2 Nasoendoscopic view of bony nasal lacrimal canal. The canal is formed by the maxilla, the lacrimal bone and the inferior nasal concha.

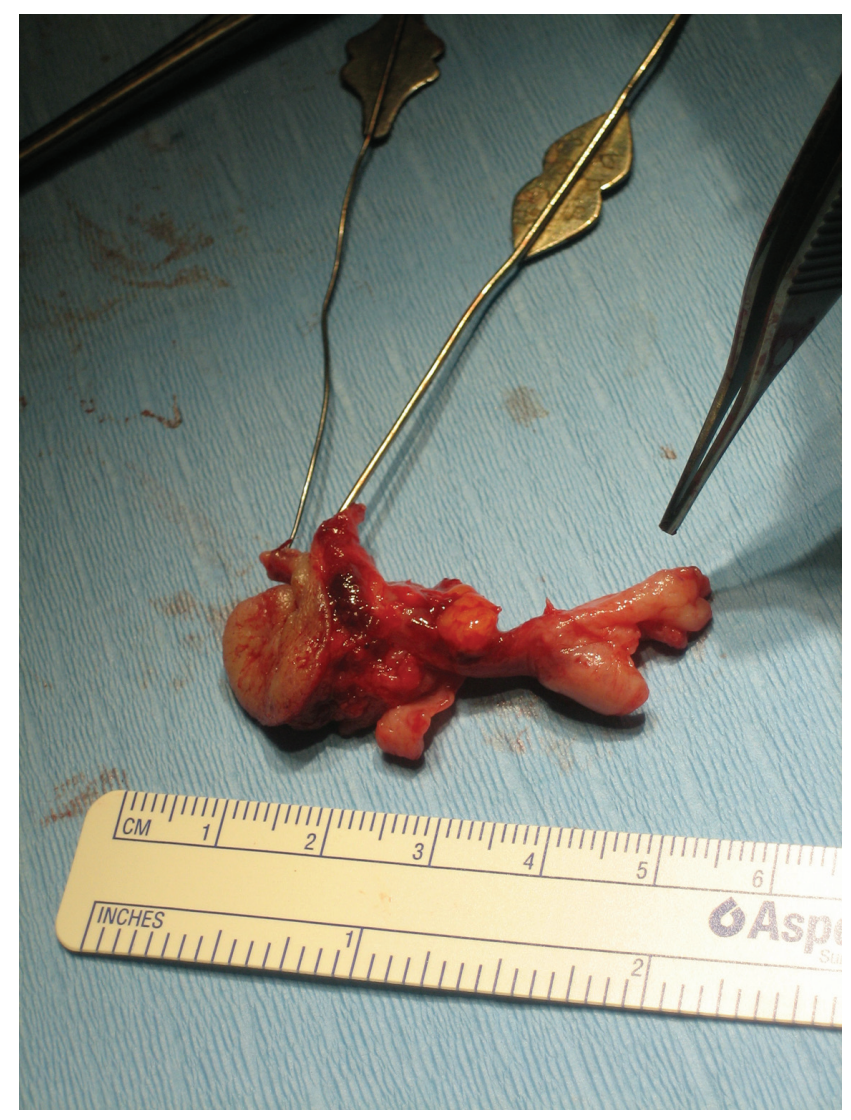

Figure 3 Gross specimen postsurgical resection of lacrimal apparatus. Upper and lower lid canaliculi are visible with probes in situ. The lacrimal sac and duct was resected intact and the gross specimen sent for histopathology.

cell carcinoma with focal squamous differentiation (nonkeratinizing cell carcinoma). The tumor was mostly noninvasive with isolated foci of stromal invasion. This high grade in situ carcinoma extended superiorly along both lacrimal canaliculi and inferiorly along the nasolacrimal duct. All margins were clear with appearance of complete excision (Figures 4-6).

\section{Follow up}

At postoperative day 10 , the patient noted a satisfactory cosmetic effect (Figures 7, 8). No radiotherapy was given postoperatively. An ophthalmology review in August 2007 revealed persistent left-sided epiphora, but no other associated symptoms. Further opening of the left punctum with probe under local anesthetic was required in August 2007. This was attributed to postoperative scarring and the patient's epiphora resolved. New nasal polyps were found in both maxillary sinus with removal and revision maxillary FESS performed in November 2007. The polyps were diagnosed at a routine six-month check up with no symptoms experienced by the patient. 


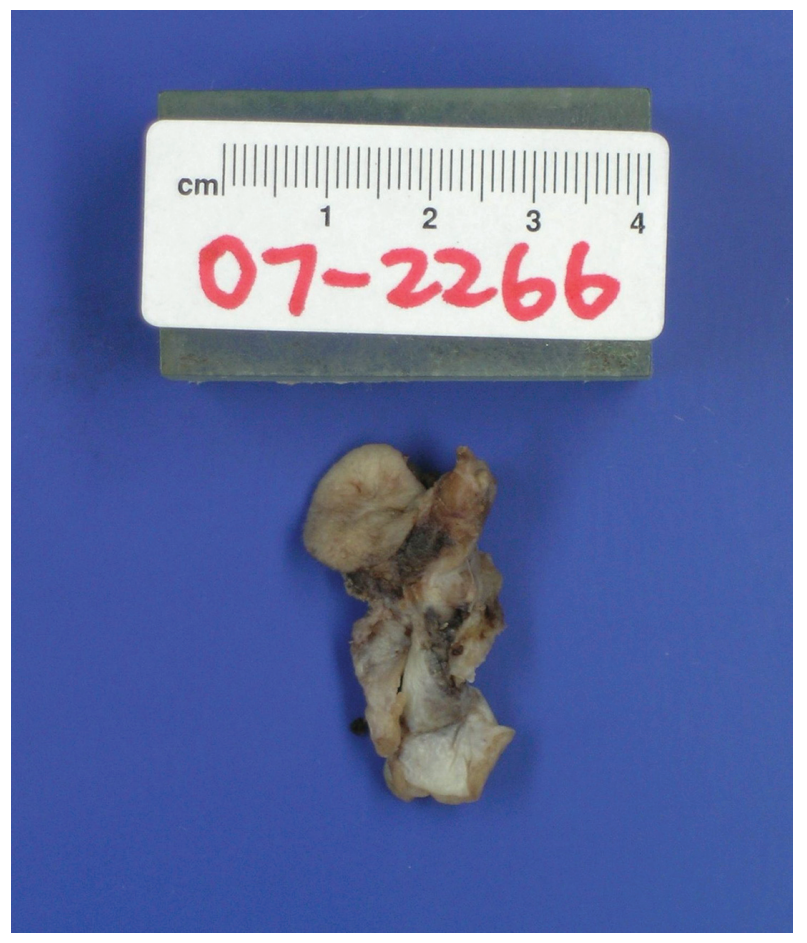

Figure $4 \mathrm{Nasal}$ lacrimal apparatus postfixation with formula for histopathology. Correct anatomical orientation. The lacrimal sac measured about $20-\mathrm{mm}$ long and connected to the inferior meatus of the nose by the nasolacrimal duct. The direction of the duct is downward, backward and lateral is lodged in the bony nasolacrimal canal.

The patient was noted to be symptom free in August 2009. Continued follow-up will be pursued to monitor future recurrence rates (Figures 7,8 ).

\section{Discussion}

Primary carcinomas of the lacrimal sac are rare with less than 30 transitional cell carcinomas described in

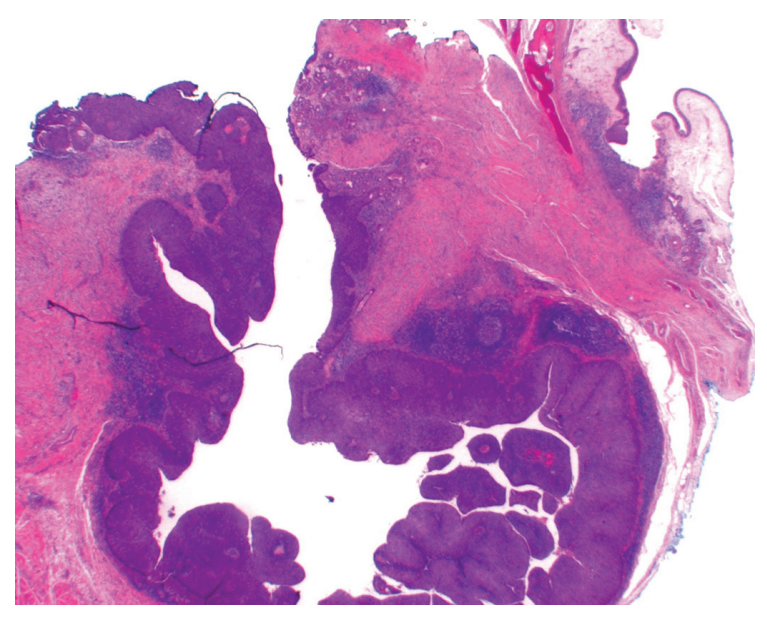

Figure 5 Hematoxylin and eosin stain with low power magnification of the nasolacrimal sac. This was lined by a malignant papillary epithelial tumor. The tumor was mostly noninvasive with isolated foci of stromal invasion.

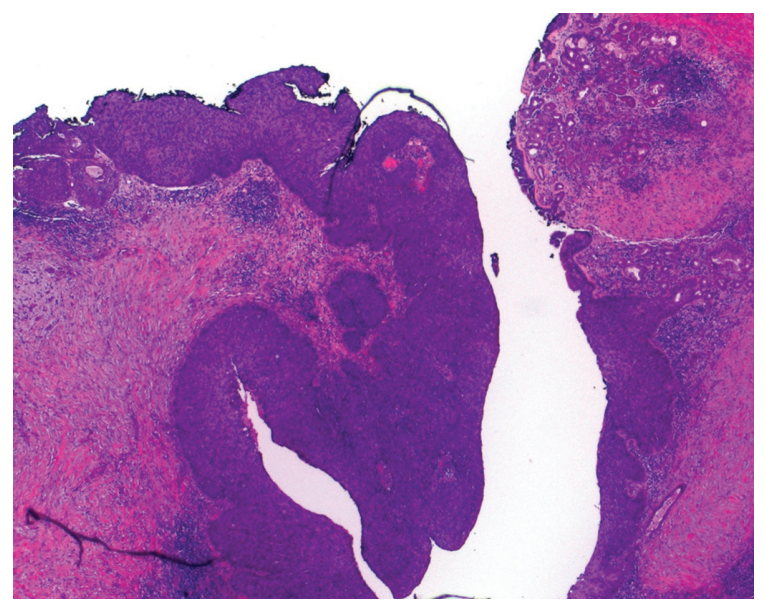

Figure 6 Higher power magnification (hematoxylin and eosin stain x80). Distinct features of transitional cell carcinoma were noted on microscopy with focal squamous differentiation (nonkeratinising cell carcinoma) High grade in situ carcinoma extended superiorly along both lacrimal canaliculi and inferiorly along the nasolacrimal duct. All margins were clear with appearance of complete excision.

the medical literature. Parmar and Rose described three cases of transitional cell carcinoma and one case of mixed transitional cell carcinoma and squamous cell carcinoma. ${ }^{1}$ $\mathrm{Ni}$ and colleagues reviewed 82 patients with tumors of the nasolacrimal sac and found only six cases of transitional cell carcinoma. ${ }^{2}$ Stefanyszyn and colleagues documented only five transitional cells carcinomas out of 115 lacrimal sac tumors. ${ }^{3}$

The lacrimal sac is situated in the lacrimal fossa surrounded by lacrimal bone and the frontal process of the maxilla. ${ }^{4}$ As the sac is hidden within the anterior part of the medial wall of the orbit, tumors are hard to detect until there is functional blockage of the nasolacrimal duct or a mass effect noted. Tumors thus have a more insidious presentation with common symptoms of dacryocystitis and nasolacrimal duct obstruction. Epiphora may or may not be present. Patients may occasionally notice facial asymmetry and a painless swelling at the medial canthus. Hornblass and colleagues ${ }^{5}$ described a possible anatomical increased suspicion of malignancy with masses superior to the medial canthal tendon. Masses inferior to the medial canthus were more likely to be an inflammatory reaction. Suspicion of tumor is common at time of surgical exploration during dacryocystorhinostomy surgery as was suspected in our case. Flanagan and colleagues revealed that $43 \%$ of lacrimal sac tumors were found inadvertently at the time of dacryocystorhinostomy. ${ }^{6}$ Anderson and colleagues reviewed 377 specimens and found that neoplasms resulting in chronic nasolacrimal duct obstruction occurred in $4.6 \%$ of cases and were unsuspected before surgery in $2.1 \%$ of patients. ${ }^{7}$ Associated proptosis and hemorrhagic discharge 


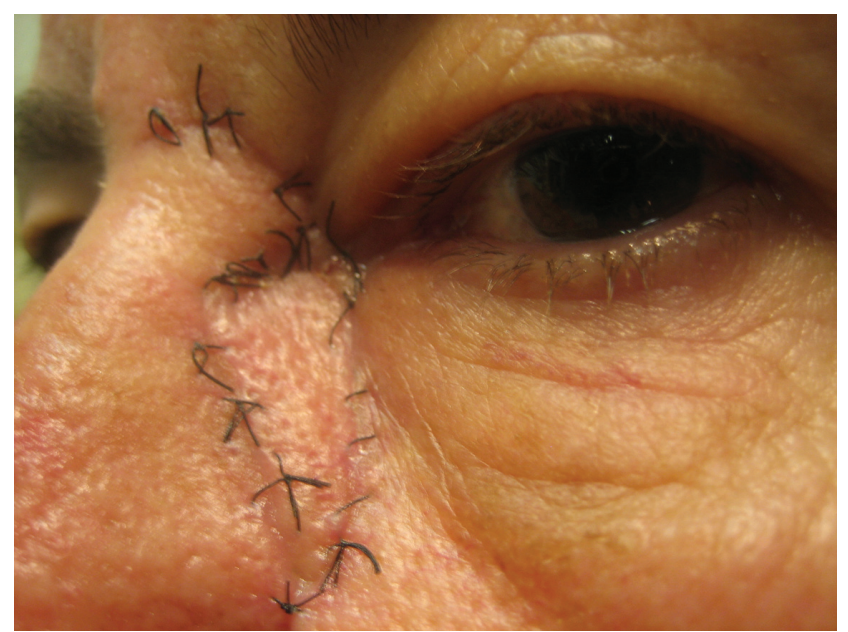

Figure 7 Ten days postoperative follow-up: satisfactory cosmetic result.

from the tear duct are symptoms with a higher index of suspicion for lacrimal sac tumors. They were found to be late signs by Stefanyszyn and Ni. ${ }^{2,3}$

The mean age of those afflicted with transitional cell carcinoma was $47-50$ years, similar to other lacrimal sac tumors which mainly occur in the fourth to fifth decade of life. Benign transitional cell papillomas were found to occur earlier at the age of 40 years. ${ }^{2,3}$ Anderson and colleagues described a case of invasive transitional cell carcinoma of the lacrimal sac arising from an inverted papilloma in a 36-year-old patient ${ }^{8}$ and $\mathrm{Ni}$ and colleagues confirmed one case of transitional cell carcinoma in a 20 -year-old patient. ${ }^{2}$ This highlights the possibility of malignancy in younger populations. There were no statistically significant differences in occurrence of transitional cell carcinoma between males and females.

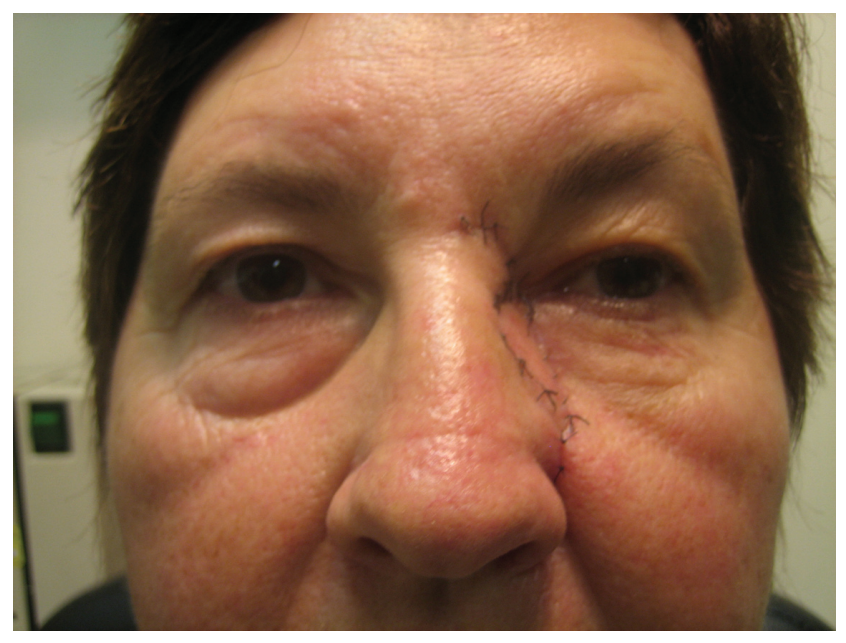

Figure 8 Ten days postoperative follow-up: satisfactory cosmetic result.
Computed tomography and magnetic resonance imaging (MRI) scan is important to delineate tumor size and the extent of bony destruction. Callender and colleagues confirm that computer tomography is a useful tool for diagnosing lacrimal sac tumors and identification of tumor extension to surrounding structures. ${ }^{9}$ A mass lesion was seen on a computed tomography scan in our case. However, the computed tomography scan was only performed after initial dacryocystorhinostomy surgery when a suspicion of malignancy was raised.

Suspected lacrimal drainage system malignancy is confirmed by histopathology from biopsy or resection of the nasolacrimal apparatus. Most authors recommend a standard dacryocystorhinostomy approach to the lacrimal fossa with wide excision. ${ }^{2,3,5,10}$ The recommended procedure performed in our case was complete resection of the nasolacrimal sac, and both upper and lower canaliculi and nasolacrimal duct for complete clearance. Upper and lower ethmoidectomy and partial maxillectomy were also recommended for extending mass and satellite lesions. ${ }^{1-3,5}$ Adjuvant radiotherapy is recommended for unrecognized local extension and microscopic residual disease. Primary radiotherapy is not recommended with $\mathrm{Ni}$ and colleagues describing a five-year mortality rate of $43.7 \%$ in three cases. ${ }^{2}$

Transitional cell carcinomas have a poor prognosis. $\mathrm{Ni}$ and colleagues described remote metastasis with transitional cell carcinoma despite extensive resection. ${ }^{2}$ This may be attributed to a delay in diagnosis from late discovery of the malignancy. Ni and colleagues found $100 \%$ of transitional cell carcinomas reviewed resulted in death from recurrence. ${ }^{2}$ Stefanyszyn and colleagues described five patients with transitional cell carcinoma with two displaying local recurrence and subsequent mortality. ${ }^{3}$ Despite extensive wide excision and radiotherapy, one patient died of lung metastasis four years after diagnosis. ${ }^{3}$ Preechawai and colleagues reviewed the literature and described one third of patients having recurrent disease with a $22 \%$ rate of distant metastasis to the lungs and esophagus. ${ }^{11}$ This high recurrence rate was described as being due to, in part, inadequate initial treatment and late detection. The overall mortality rate quoted by Preechawai and colleagues is $44 \%{ }^{11}$ Parmar and Rose described a similar mortality of $37.5 \%$ for all epithelial tumors despite reported wide surgical excision and radiotherapy. ${ }^{1}$ Like other carcinomas, prognosis for these malignancies is influenced by the size and local extension of the tumor and by the presence or absence of metastases. Tumor histology most likely influences prognosis. Out of the malignant epithelial neoplasm, squamous cell carcinomas are the most common. There are only a small number of documented 
cases of transitional cell carcinomas. Good prognostic factors in the histopathology include well differentiated cells with uniform columnar cell, rare mitotic figures, and an intact basement membrane. Poor prognosis occurs when tumor tissue displays marked pleomorphism, squamous metaplasia, numerous mitotis figures, and areas of stromal invasion on histopathology examination. ${ }^{10}$

Transitional cell carcinoma in the lacrimal sac is a rare yet important disease due to their malignant and potentially lethal outcomes especially if there is a misdiagnosis or delay in treatment. Diagnosis is difficult due to the hidden anatomical location of the nasolacrimal system. Symptoms related to pathology have an insidious onset and occur in chronic inflammatory conditions of the nasolacrimal system as well. One should have a high index of suspicion in patients presenting with chronic low grade dacryocystitis without purulent discharge and epiphora. Computed tomography should be employed in those suspected of a lacrimal sac tumor for visualization of tumor size and extension preoperatively. Wide excision of the whole nasolacrimal apparatus with associated functional endoscopic sinus surgery is recommended with or without adjuvant radiotherapy. Longer term follow up and surveillance is essential as regional and distant metastases are consistently documented in the medical literature during original resections.

\section{Disclosures}

The authors report no conflicts of interest in this work.

\section{References}

1. Parmar DN, Rose GE. Management of lacrimal sac tumours. Eye. 2003;17:599-606.

2. Ni C, DûAmico DJ, Fan CQ, Kuo PK. Tumors of the lacrimal sac: a clinicopathological analysis of 82 cases. Int Ophthalmol Clin. 1981;22:121-140.

3. Stefanyszyn MA, Hidayat AA, Peûer JJ, Flanagan JC. Lacrimal sac tumors. Ophthal Plast Reconstr Surg. 1994;10:169-184.

4. Snell R, Lemp M. The Ocular Appendages: The lacrimal sac, clinical anatomy of the eye. 2 nd edition. 1998. p. 120.

5. Hornblass A, Jakobiec FA, Bosniak S, Flanagan J. The diagnosis and management of epithelial tumors of the lacrimal sac. Ophthalmology. $1980 ; 87: 476-490$

6. Flanagan JC, Stokes DP. Lacrimal sac tumors. Ophthalmology. 1978;85:1282-1287.

7. Anderson NG, Wojno TH, Grossniklaus HE. Clinicopathologic findings from lacrimal sac biopsy specimens obtained during dacryocystorhinostomy. Ophthal Plast Reconstr Surg. 2003;19:173-176.

8. Anderson KK, Lessner AM, Hood I. Invasive transitional cell carcinoma of the lacrimal sac arising in an inverted papilloma. Arch Ophthalmol. 1994;112:306-307.

9. Callender DL, Frankenthaler RA, Weber RS, Dodd L, Batsakis JG. Carcinomas of the lacrimal drainage system. Head Neck. 1993;15: 313-319.

10. Pang C, Brown JD, Ganote CE, Youngberg GA. A mass of the right lacrimal sac in a 53-year-old man. Arch Pathol Lab Med. 2005; 129:1493-1494.

11. Preechawai P, Della Roccad RC, Della Rocca D, Schaefer S, McCormack S. Transitional cell carcinoma of the lacrimal sac. J Med Assoc Thai. 2005;88:138-142.
Clinical Ophthalmology

\section{Publish your work in this journal}

Clinical Ophthalmology is an international, peer-reviewed journal covering all subspecialties within ophthalmology. Key topics include: Optometry; Visual science; Pharmacology and drug therapy in eye diseases; Basic Sciences; Primary and Secondary eye care; Patien Safety and Quality of Care Improvements. This journal is indexed on

Submit your manuscript here: http://www.dovepress.com/clinical-ophthalmology-journal

\section{Dovepress}

PubMed Central and CAS, and is the official journal of The Society of Clinical Ophthalmology (SCO). The manuscript management system is completely online and includes a very quick and fair peer-review system, which is all easy to use. Visit http://www.dovepress.com/ testimonials.php to read real quotes from published authors. 